measures. Several descriptions of comparing apparatus with micrometer microscopes have been constructed at various times, but all are made upon the same principle. The microscope is fixed in a vertical position, and is provided with a spirit level and with screws for accurate levelling and focal adjustment. The defining marks of the two standard measures to be compared are brought successively under it, their height being adjusted to the focal distance of the microscope. Any difference of length between the defining marks of the two measures is read off from the graduated head of the micrometer. This part of the apparatus consists of an endless screw with the very finest threads, having a large head divided into 100 parts. The screw is placed in a horizontal position, and when turned carries with it a nut moving in horizontal guides, together with an open frame, which has cobweb lines stretched across it. Two of these lines $(b b$ Fig. 20) cross each other at equal angles to the axis of the screw, and so that a line bisecting them is normal to its axis. Two other lines $(c c)$ are placed nearly close, and parallel to each other and normal to the axis of the screw; and there are two longitudinal lines (d d) parallel to the axis of the screw, by means of which this axis is made parallel to the axis of the measure under observation. When turning the screw, the number of revolutions is read off by the aid of a pointer from a rack $(a)$ placed at the edge of the open frame and parallel to the screw, whilst the number of divisions in one revolution is read off on the graduated head of the screw, from a fixed line marked on the upper surface of the microscope. Looking through the eye-piece of the microscope at the magnified first ten hundredths of the inch $36-37$ marked on the subdivided standard yard of the Standards' Department (here inverted), the field of the microscope is seen as represented in Fig. 20.

In this figure the cross lines are used for observation, and are seen adjusted to the 0.03 in. line. The pointer at the rack shows the screw to be turned between one and two revolutions from the middle of the field.

All micrometer microscopes used for the comparison of standard measures of length are constructed upon the principle thus described. But there are various kinds of arrangements for supporting the standard measures in a proper position, and for more conveniently bringing their defining marks under the microscopes. Under one of the arrangements, a single micrometer microscope is used, and fixed over the supporting apparatus, which, for the purpose of comparison, has both a transversal and a longitudinal displacement.

The two standard measures (denoted as $A$ and $B$ ) being placed with their axes exactly parallel, and their defining marks as nearly as possible in the same line normal to the axes, the left-hand defining mark of $A$ is brought under the microscope, and the position of the micrometer read off on the index scale and noted. By the transversal displacement, the left-hand defining mark of $B$ is next brought under the microscope, and the reading of the index scale noted. The two measuring bars are then moved their whole length by longitudinal displacement, and the right-hand defining marks of $A$ and $B$ successively read off and noted, thus affording the means of ascertaining the difference of length of the two standard measures. The temperature of the bars at the beginning and end of the observations must be determined by thermometers, and the mean temperature noted, and allowance must be made by computation for any difference of length arising from unequal expansion or contraction of the two bars, when this temperature differs from the standard temperature. For this purpose it is absolutely necessary that the coefficient of expansion of each standard bar must be previously determined.

This method of comparing with a single microscope is used in France, but not in England, where the risk of error arising from the longitudinal movement of the bars is avoided by using two microscopes, and only a transversal displacement of the bars during the observations, although there are also means of longitudinal displacement for the purposes of adjustment. The objection raised against the use of two microscopes, that the distance between them may vary during the period of observation by the expansion or contraction from alteration of temperature of the material which unites them, is obviated by fixing them firmly and independently upon a solid stone support.

Placing measuring bars directly upon a plane support is objectionable. It has been proved that there is a risk of discordances in comparisons being caused by almost undiscoverable inequalities in planed surfaces, as well as by a difference of temperature in the plane surface and the under surface of the measuring bar, when thus placed. To guard against this risk, the bars are supported upon rollers, and the measuring bars ought to be stiff enough to bear to be supported upon a few points at which rollers can be conveniently applied. For a short bar two rollers are sufficient; for a longer bar more supports are required. The standard yard bars are supported upon eight rollers, and it is always requisite that each support should exert the same vertical pressure upwards, in order that the interval between two points upon the surface of the bar may not be altered by the flexure. This object is attained by a proper arrangement of levers ; and it is easily seen that an arrangement of levers by which equal pressure upwards may be exerted at four or eight points is very simple. Each bar rests upon two brass lever-frames.

It has been shown by the Astronomer Royal, in his paper printed in the Royal Astronomical Society's Memoirs, vol. xv., that the value of the intervals (supposed equal) which ought to exist between different supports of a bar, each support exerting the same vertical pressure upwards, is as follows : $n$ being the number of supports, the resulting intervals of supports is :-

$$
\frac{\text { length of bar }}{\sqrt{\left(x^{2}-1\right)}}
$$

In order to ascertain with scientific precision how far the results of comparisons of standards obtained by the use of weighing and measuring instruments are to be depended upon for their accuracy, a calculation is to be made of the probable error of every such result, whether it be the result of a single comparison, or the mean result of any number of comparisons. And when other elements are to be taken into account, it is necessary that the probable error of each computation should be determined and allowed for before the final results of comparison can be determined and allowed for.

The mode generally adopted for calculating the probable error is based upon the method of least squares, and is fully stated by the Astronomer Royal, in his "Theory of Errors of Observation," pp. 44-7.

\section{H. W. CHISHOLM}

\section{EARTH-SCULPTURE* *}

II.

YOU are aware that the revival of the half-forgotten doctrines of the early Scottish School of Geology has not been without vehement protest on the part of the older geologists, who have been inclined to treat them rather as novelties and departures from the older and purer faith. No one resisted them more determinedly than my much-missed friend and benefactor, the late Sir Roderick Murchison. He looked with regret, and even, perhaps, sometimes with a little alarm, upon their advance, and to the last he battled against them. He was, indeed, in this country the leader of his party, which has been called the "Convulsionist School," and his death

* Opening Address to the Edinburgh Geological Society, by Prof. Geikie F.R.S. (continued from p. 52 ). 
has, doubtless, been a severe blow to that school, as it has been a loss to all who admired a straightforward, courteous, and undaunted antagonist.

Other members of the party have, however, in more or less direct ways, lifted up their voices of protest. I select this evening one of these antagonists, partly because he has spoken more and more energetically than any other, and partly because a good deal of his speaking has been directed against myself. And here I am sorry that I must begin by a reference to a matter of personal history. In the summer of 1865 I published a little volume, now out of print, on "The Scenery of Scotland, viewed in connection with its Physical Geology." The object of that work was to show how completely the Huttonian doctrine of earth-sculpture was borne out by the mountains and valleys of the northern part of this island. I distinctly disclaimed any novelty or originality on my own part in the broad doctrine which $I$ tried to enforce. My veneration for Hutton and Playfair had been from boyhood profound; again and again in the pages of my book $I$ quoted them, and spoke of them as the founders of the school to which I professed myself a loyal adherent, and in which I could boast such friends and colleagues as Jukes and Ramsay.

I was well aware, and stated in the preface, that the views to which I had been led "ran counter to what are still the prevailing impressions on this subject," and that I was prepared to find them disputed, or thrown aside. Convinced, however, of their essential truth, I looked forward to a time when what might then be regarded as mere dreaming would be established as a recognised part of the groundwork of geology. The views put forward in the volume met, indeed, with an amount of general acceptance which I could hardly have anticipated. But at length the expected opposition made its appearance.

On February 3, I868, his Grace the Duke of Argyll read to the Geological Society of London a paper, entitled "On the Physical Geography of Argyleshire, in connection with its geological structure." Although that title was chosen, the paper proved really to be from beginning to end a criticism of my little book, which, indeed, the author candidly acknowledged to have served him as "the best text he could find."

To that paper I made no reply. It seemed to me that the noble author had failed to perceive the bearing of the whole argument from geological waste, as proved by geological structure. His objections being already, in my opinion, anticipated ir the book which had called them forth, I did not see how I could make my case plainer by any amount of additional argument. But further, his Grace had begun his communication with a sentence in which he stated that the views set forth by me "seemed to be gaining ground with the younger school of geologists,"-fatal admission, as it occurred to me, for I felt that what was called the younger school must eventually take the place of that which styled itselt the older, and that if it remained true to its belief, the views which were now called in question would carry the day without any battling of mine. Every month shows more fully the justice of this anticipation.

I was content to let the matier rest; nor would I recur to it now, but for the following reasons, Since that time the Duke of Argyll has become President of the Geological Society of London. In his recent address, and in a separate communication to the Society, he has returned to the subject of the origin of the present features of the land, referring to his former paper as "an argument which had not been met by any answer in detail," and adhering, therefore, to the views there expressed. As to the nonappearance of any "answer in detail" from myself, I can give no other explanation than that I considered my little book sufficiently detailed for its purpose, and believed that it already anticipated and answered the argument of my opponent. That is still my belief.
But a broad challenge addressed to the general body of geologists by the President in the official Address which he annually gives to the Society and the world, is not the same thing as a criticism from one member of the Society upon the work of another member. In the interests of science, therefore, it seems to me that some protest is now called for against doctrines promulgated at this late date in the century from so high and honourable position as the Chair of the Geological Society of London; and as $I$ have been especially singled out for attack, it appears to me to be only an act of duty to vindicate, not my own position merely, but the reputation of that "younger school" which is accused of seeking to pervert the geological mind from the ancient and true creed. If these doctrines maintained by the President were to become generally diffused, which, happily, is now impossible, they would suffice to paralyse research in one important branch of the science; for, as far as relates to the history of the configuration of the land, they would assuredly bring down upon us again the pre-Huttonian darkness.

No one whom the Geological Society of London has chosen as its President can fail to command the respectful attention of geologists all over the world. And while I gladly acknowledge this right, I would also express the gratification which is widespread among the brethren of the hammer in this country that the Duke of Argyll, in the midst of so many and so onerous, as well as honourable duties, should find time to take a lively and active interest in the progress of geology. I admire, too, the vigour with which he wields his pen, and the boldness with which he gives his judgment among disputed questions. He has once more thrown down his geological gauntlet, and if I venture to take it up, and accept his battle, it is in the full consciousness of the presence of an adversary who, while dealing hard blows himself, will take in good part such buffets as the fortunes of war may bring to him.

I have already alluded to the natural impression that when we look at a region of rough mountains formed out of hardened and contorted rocks, we behold in the external outlines the direct results of the subterranean force by which the rocks were altered and crumpled. This obvious inference is far older than the days of geological inquiry. But surely its mere obviousness is no argument for its truth, any more than the rising and setting of the sun prove the earth to be the centre of the universe. In the volume already referred to I spoke of it as "dealing with that dreamland of conjecture and speculation lying far beyond the pathways of science, where one has no need of facts for either the foundation or superstructure of his theory. It thus requires no scientific knowledge or training ; it can be appreciated by all, and may be applied to the history of a mountain chain by one to whom the very name of geology is unknown." But to recognise that this common and instinctive notion is yet a misleading one, requires an acquaintance with geological structure which comparatively few have an opportunity of obtaining, and which appears to be not always readily acquired at second-hand. I have watched the current geological literature on this question during the last decennium, and the result has been to convince me that the notion, or rather the prejudice which I am combating, is in some minds so deeply rooted that it cannot be got rid of by the reading of any number of books or treatises, and, of course, still less by the writing of them. Simple as may be the statement of the leading principles and facts relative to that waste of the earth's surface to which the term Denudation is applied, there is yet, I firmly believe, no part of geology more difficult adequately to realise. So striking are the difference and contrast between the magnitude of the results adduced and the apparent insignificance and impotence of the forces which are alleged to have produced them, that the mind not unnaturally hesitates to associate the one with the other in the rela- 
tion of cause and effect. And yet it is only in proportion tion of cause and to master this subject that he is preas one is enabled far less to discuss the origin of the present contours of the land.

present contoume which the Duke of Argyll has singled In the brunt of his attack, I carefully stated at out to bearencement that I proposed to consider the problem only "in so far as it relates to the history of the scenery of Scotland." I laid down no universal law or dogma by which the hills and valleys of every other part dog the world were to be explained. I knew the mountains and glens of Scotland; I had wandered over them and studied them from boyhood; trained in the severe and laborious school of the Geological Survey, I had mapped many hundreds of square miles of their surface, across some of the most complicated pieces of geological structure in the kingdom. It was not, therefore, in any spirit of rashness, or novelty, or dogmatism, but with the growing convictions of many years of experience and in the belief that a service to the cause of geological inquiry in this country could be done, that I ventured to launch my little book upon the world. I was well aware that other regions exhibited features not seen here, and that for these other explanations might require to be found. But it was then no part of my subject to travel beyond my own domain. When the principles for which, in common with my able colleagues in the Survey, I contended were firmly established in relation to the scenery of this country, it would then be time to consider how far they were applicable elsewhere. That they would be found to be not merely of local but of wide general import I then held to be probable, and I now know to be profoundly true.

One main object of my chapters was to show how the present hills and valleys of Scotland had come into existence gradually, one by one, during an enormously protracted period of geological waste in the manner to which I have already referred this evening. I adduced copious proofs from all parts of the kingdom in suppert of this view, similar proofs having been already triumphantly accumulated by Mr. Jukes in Ireland, and by Prof. Ramsay and others in England.

Far from ignoring the influence of geological structure upon external form, I might even have been charged with having brought forward a needlessly ample accumulation of evidence to show how constantly the resulting contours of the country have been determined by the arrangement of the rocks. I showed how ancient, in a geological sense, the denudation of the country had been, and how thoroughly it had done its work upon the surface, no matter whether the rocks had been originally formed as mere soft mud or had been once in actual fusion. I dwelt on the remarkable fact that as a rule the valleys do not run along lines of fracture, and quoted in support of this assertion the published maps of the Geological Survey of the three kingdoms. To these and similar statements of sober fact which are now part of the common stock of geological knowledge, his Grace opposes such phrases as these: "The facts assumed are, in my opinion, to a large extent purely hypotbetical," "This assertion is erroneous," " extravagant demands," "inventions and imaginations," and so on.

\section{(To be continued.)}

\section{NOTES}

THE annual meeting of the Fellows of the Royal Society was held on Tuesday at Burlington House. The retiring President, Sir George Biddell Airy, K.C.B., delivered the inaugural address. The presentation of the medals followed. The Copley Medal was awarded to Professor Helmholtz, the distinguished physiologist, physicist, and mathematician, of Berlin, "whose memoirs have ranged through nervous physiology, hydrodynamical theory, instruments (as the ophthalmometer and the ophthalmoscope) for exact measurement and for medical examination of the eye, and other important subjects, and have been generally recognised as giving real additions to our knowledge." A Royal Medal was awarded to Prof. Allman, F.R.S., "for his numerous zoological investigations, and more especially for his work upon the Tubularian Hydroids. The subject of these labours is one upon which few persons are qualified to enter; and the Council are impressed with the delicacy of the work and the value of the scientific results." A Royal medal was awardep to Protessor H. E. Roscoe, F.R.S., of Owens College, Mar. chester, "for his various Chemical Researches, more especially for his investigations of the Chemical Action of Light, and of the Combinations of Vanadium." Dr. Joseph Dalton Hooker, C.B., was elected President of the Society.

THE alleged reply of the Government on the subject of an Arctic Expedition as reported in the daily papers (Daily Telegraph and Pall Mall Gazette) is calculated to convey a very erroneous impression. Mr. Gladstone has requested that he may be furnished, in writing, with the reasons for the despatch of an Arcic Expedition, before receiving a deputation on the subject. Those reasons, which we believe to be quite conclusive as showing the propriety of despatching an expedition next year, will at once be furnished to the Prime Minister.

Prof. A. W. Williamson has been elected a Correspondent of the French Academy.

ThE Duke of Northumberland has been unanimously electcd President of the Royal Institution, in succession to the late S: $r$ Henry Holland.

THE probable arrangements for the Friday Evening Meetings of the Royal Institution before Easter 1874 , are as follows :Jan. 16: The Acoustic Transparency and Opacity of the Atmo. sphere, by Prof. Tyndall, F.R.S. Jan. 23: Recent Discoveries in Mechanical Conversion of Motion, by Prof. Sylvester, F.R.S. Jan. 30: Weber and his Times, by Sir Julius Benedict. Feb. 6: The Heart and the Sphygmograph, by Alfred H. Garrod, Fellow of St. Jolnn's College, Cambridge. Feb. I3: The Opponents of Shakespeare, by Dr. Doran, F.S.A. Feb. 20: The Autotype and other Photographic Processes and Discoveries, by Vernon Heath. Feb. 27: Men of Science, their Nature and Nurture, by Francis Galton, F.R.S. March 6 : Venus's Fly-trap, by Dr. J. S. Buidon-Sanderson, F.R.S. March I3: Graphic Representations of Musical Sounds, by M. Cornu. March 20: The Temperature of the Atlantic, by Dr. W. B. Carpenter, F.R.S., Registrar Univ. Lond. March 27: The Physical History of the Rhine, by Prof. A. C. Ramsay, F.R.S., Director of the Geological Survey of Great Britain.

Sir Samuel Baker has quite recovered from his recent indisposition, and will on Monday next address the Royal Geographical Society upon his adventures in Africa.

WE regret to announce the death of $\mathrm{M}$. De La Rive at hiarseilles on Nov. 27 , on his way to Cannes. He had had an apoplectic fit about a fortnight previously, from which he seemed to be slowly recovering, though greatly shattered in intellect.

WE rejoice to learn that at a convocation held at Oxford on Noyember 27 , the grant alluded to in NATURE a fortnight ago in connection with Dr. De La Rue's gift of astronomical apparatus to the University, was acceded to in a manner creditable and gratifying to all concerned. Thus the University has, we believe, established the foundation of what ought to become a very useful Observatury for A. . tronomical Physics. One immediate result, we hope, will be to excite Cambridge into vigorous action. Oxford deserves great credit for the efforts she has made during the 